\title{
Does a preceding hand wash and drying time after surgical hand disinfection influence the efficacy of a propanol-based hand rub? Nils-Olaf Hübner ${ }^{1}$, Günter Kampf ${ }^{1,2}$, Philipp Kamp ${ }^{1}$, Thomas Kohlmann ${ }^{3}$ and Axel Kramer*1
}

Address: ${ }^{1}$ Institute of Hygiene and Environmental Medicine, Ernst Moritz Arndt University, Walther-Rathenau-Str. $49 a$, 17489 Greifswald, Germany, ${ }^{2}$ BODE Chemie GmbH \& Co. KG, Scientific Affairs, Melanchthonstrasse 27, 22525 Hamburg, Germany and ${ }^{3}$ Institute for Community Medicine, Ernst Moritz Arndt University, Walther-Rathenau-Str. 48, 17487 Greifswald, Germany

Email: Nils-Olaf Hübner - nh778@web.de; Günter Kampf - guenter.kampf@bode-chemie.de; Philipp Kamp - Ph.Kamp@web.de; Thomas Kohlmann - kohlmann@uni-greifswald.de; Axel Kramer* - kramer@uni-greifswald.de

* Corresponding author

Published: 22 June 2006

BMC Microbiology 2006, 6:57 doi:10.1|86/|47|-2/80-6-57
Received: 23 November 2005

Accepted: 22 June 2006

This article is available from: http://www.biomedcentral.com/I47I-2/80/6/57

(c) 2006 Hübner et al; licensee BioMed Central Ltd.

This is an Open Access article distributed under the terms of the Creative Commons Attribution License (http://creativecommons.org/licenses/by/2.0), which permits unrestricted use, distribution, and reproduction in any medium, provided the original work is properly cited.

\begin{abstract}
Background: Recently, a propanol-based hand rub has been described to exceed the efficacy requirements of the European standard EN I279I in only 1.5 min significantly. But the effect of a I min preceding hand wash and the effect of one additional minute for evaporation of the alcohol after its application on the efficacy after a $1.5 \mathrm{~min}$ application time has never been studied.
\end{abstract}

Methods: We have investigated a propanol-based hand rub (Sterillium ${ }^{\circledR}$, based on $45 \%$ propan-2-ol, $30 \%$ propan-I-ol and $0.2 \%$ mecetronium etilsulfate) in three variations: with (A) and without (B) a I min hand wash before the disinfection of $I .5$ min with immediate sampling after the disinfection; and (C) without a hand wash before the disinfection but with sampling I min after the disinfection. The efficacy of the three variations was compared to the reference treatment of EN 1279I. All experiments were performed in a Latin-square design with 20 volunteers. Pre- and post-values (immediate and after $3 \mathrm{hr}$ ) were obtained according to EN 12791.

Results: The $3 \mathrm{~min}$ reference disinfection reduced resident hand bacteria on average by $1.8 \log _{10}$ steps (immediate effect) and $1.4 \log _{10}$-steps (sustained effect) respectively. Method $A$ was equally effective as the

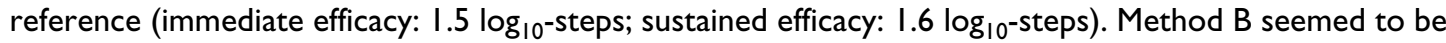
more effective (immediate efficacy: $2.3 \log _{10}$-steps; sustained efficacy: $1.7 \log _{10}$-steps). Method $C$ revealed the best efficacy (immediate efficacy: $2.3 \log _{10}$-steps; sustained efficacy: $2.0 \log _{10} 0^{\text {-steps) }}$. A comparison of all three treatment variations and the reference treatment revealed a significant difference for the immediate efficacy $(p=0.026$; Friedman test), but not for the sustained efficacy $(p=0.430)$. A post-hoctest for the immediate efficacy indicated a significant difference between methods $A$ and $C(P<0.05$; Wilcoxon-Wilcox test). Hence, none of the treatment variations was significantly less effective than the reference treatment.

Conclusion: An application of the propanol-based hand rub for $1.5 \mathrm{~min}$ after I min hand wash fulfills the efficacy requirements of EN 1279I. The efficacy can be improved to some extent by omitting the preceding hand wash and by awaiting the evaporation of the alcohol which is clinical practice anyway. The preceding hand wash has the most negative effect on the immediate effect. Based on our data hands should not be routinely washed before the disinfection period unless there is a good reason for it such as visible soiling. 


\section{Background}

Alcohol-based hand rubs are recommended and widely used for surgical hand disinfection in many countries $[1,2]$. The main aim of the pre-operative treatment of hands is the reduction of resident skin bacteria to a minimum in order to reduce the risk of surgical site infections in case of perforated surgical gloves [3]. Alcohols are considered to have better antimicrobial efficacy and dermal tolerance which are two clear advantages in comparison to antimicrobial soaps [4,5]. The application time for alcohol-based surgical hand rubs has become shorter over the last decades, and there was increasing evidence that with well-formulated hand rubs an equivalent efficacy on the resident hand flora can be achieved at an application time of $1.5 \mathrm{~min}[6,7]$. At the same time evidence was cumulating to suggest that a $1 \mathrm{~min}$ hand wash which is recommended and often performed before the disinfection period may reduce the efficacy of the alcohol to some extent [8]. But this effect has so far only been studied for a 3 min application time of the hand rubs. The influence of a preceding hand wash as well as of drying by evaporation of the hand rub on the efficacy of disinfection with an application time of $1.5 \mathrm{~min}$ is unknown. Therefore, these influences were studied by determination of the efficacy of a hand rub according to EN 12791 and compared with the 3 min reference treatment [9]. The test design of EN 12791 ensures that the treated hands are sampled immediately after the specific application time even if they are still wet with the hand rub. In clinical practice, however, it is recommended for healthcare workers to put on surgical gloves only onto dry hands due to a better skin tolerance and a lower risk for impairment of glove integrity $[2,10]$. Therefore, the test design of EN 12791 does not reflect the clinical practice of surgical hand disinfection in that particular point.

\section{Methods}

\section{Products and application}

The following preparations were used: propan-1-ol (60\%, $\mathrm{v} / \mathrm{v}$ ) as reference alcohol of EN 12791, and Sterillium based on $45 \%(\mathrm{w} / \mathrm{w})$ propan-2-ol, 30\% (w/w) propan-1$\mathrm{ol}$, and $0.2 \%(\mathrm{w} / \mathrm{w})$ mecetronium etilsulfate (Bode Chemie GmbH \& Co. KG, Hamburg, Germany). Sterillium was applied to the hands for $1.5 \mathrm{~min}$ as described recently [6]. The reference alcohol was applied to the hands for 3 min according according to EN 12791 [9].

\section{Wash phase}

The volunteers washed their hands with a non-medicated soap (sapo kalinus) as described by EN 12791. Thereafter hands were rinsed with running tap water and dried with a sterile paper towel.

\section{Determination of the pre-values and post-values}

Sampling, cultivation and calculation of values were done according to EN 12791. Volunteers rubbed the phalanges of one hand (randomly selected) for one minute in TSB (pre-value) or TSB with addition of 3\% Tween $80,3 \%$ saponin, $0.1 \%$ histidine, and $0.1 \%$ cysteine as neutralizers (immediate effect after disinfection or drying), because these neutralizers are shown to be effective [11]. The other hand was gloved for 3 hours for the assessment of the sustained effect. After taking off the glove sampling was done in the same way as for the immediate effect. For each volunteer the logarithmic reduction factor (RF) was obtained as the difference between the $\log _{10}$ pre-value and $\log _{10}$ post values.

\section{Disinfection phase}

Each of the 20 volunteers was treated with the reference product for $3 \mathrm{~min}$ as well as with Sterillium for $1.5 \mathrm{~min}$ utes. Between each product application, a rest period of at least one week elapsed in order to allow the reconstitution of normal skin flora.

\section{Design}

We have investigated surgical hand disinfection with Sterillium in three variations: with (A) and without (B) a $1 \mathrm{~min}$ hand wash before the disinfection of $1.5 \mathrm{~min}$ with immediate sampling after the disinfection; and (C) without a hand wash before the disinfection but with sampling $1 \mathrm{~min}$ after the disinfection. All three applications were tested in a Latin-square design against the reference treatment.

\section{Statistics}

A product is considered effective for surgical disinfection if the mean of the RF of both the immediate and sustained effect is not significantly lower than the corresponding mean RF of the reference treatment [9]. Differences in the immediate and sustained effects between the reference treatment and the three variations of product application were investigated by non-parametric Friedman tests, followed by the Wilcoxon-Wilcox procedure for pairwise comparisons. A p-value $<0.05$ was chosen to indicate a significant difference.

\section{Results}

The 3 min reference disinfection reduced resident hand bacteria on average by $1.8 \log _{10}$ steps (immediate effect) and $1.4 \log _{10}$-steps (sustained effect; Table 1) An application of the hand rub after a 1 min hand wash was equally effective (immediate efficacy: $1.5 \log _{10}$-steps; sustained efficacy: $1.6 \log _{10}$-steps). An application of $1.5 \mathrm{~min}$ of the hand rub without a 1 min hand wash was slightly more effective (immediate efficacy: $2.3 \log _{10}$-steps; sustained efficacy: $1.7 \log _{10}$-steps). Application of the hand rub for $1.5 \mathrm{~min}$ followed by $1 \mathrm{~min}$ drying time revealed the best 
Table I: Mean reduction \pm SD of the resident hand flora of 20 volunteers by reference treatment (60\% propan-I-ol for 3 min) or a I.5 min treatment with a propanol-based hand rub applied in three different modes; experiments according to EN I 279 I in a Latin-square design.

\begin{tabular}{|c|c|c|c|c|c|c|c|c|}
\hline \multirow[t]{2}{*}{ Formulation } & \multirow[t]{2}{*}{ Method } & \multicolumn{3}{|c|}{ Time (min) of } & \multicolumn{2}{|c|}{ Immediate effect } & \multicolumn{2}{|c|}{ Sustained effect } \\
\hline & & washing & disinfection & drying & RF & $\mathrm{p}$-value* & RF & $\mathrm{p}$-value* \\
\hline Propan-I-ol & $\begin{array}{l}\text { Reference } \\
\text { disinfection }\end{array}$ & I & 3 & - & $1.79 \pm 0.98$ & 0.026 & $1.42 \pm 0.90$ & 0.430 \\
\hline Sterillium & $A$ & I & 1.5 & - & $1.5 \mathrm{I} \pm 0.97 \S$ & & $1.62 \pm 0.93$ & \\
\hline Sterillium & B & - & 1.5 & - & $2.29 \pm 1.02$ & & $1.70 \pm 1.02$ & \\
\hline Sterillium & C & - & 1.5 & I & $2.32 \pm 0.93 \S$ & & $2.03 \pm 0.91$ & \\
\hline
\end{tabular}

*Comparison of all four treatments (Friedman test)

§Significant pairwise difference $(p<0.05)$ in Wilcoxon-Wilcox test

efficacy (immediate efficacy: $2.3 \log _{10}$-steps; sustained efficacy: $2.0 \log _{10}$-steps). A comparison of all three treatment variations and the reference treatment revealed a significant difference for the immediate efficacy $(\mathrm{p}=0.026$; Friedman test), but no significant difference for the sustained efficacy $(p=0.430)$. A post-hoc-test of pairwise differences for the immediate efficacy revealed only that method $\mathrm{C}$ was significantly more effective than method A ( $p<0.05$; Wilcoxon-Wilcox test). None of the pairwise comparisons of methods $\mathrm{A}$ to $\mathrm{C}$ with the reference reached statistical significance.

\section{Discussion}

For the first time it was demonstrated that the efficacy requirements of EN 12791 can be fulfilled with a propanol-based hand rub applied for 1.5 minute time with three different application procedures. The lowest efficacy was observed with a preceding $1 \mathrm{~min}$ hand wash, the highest efficacy was found without a preceding hand wash and with an additional drying time of $1 \mathrm{~min}$ after the disinfection period.

It has been shown before that a 1 min hand wash followed by drying hands with a paper towel has a significant effect on skin hydration which significantly increases for up to $9 \mathrm{~min}$ [8]. At the same time it was found that the efficacy of different types of alcohols is impaired by a hand wash to some extent [8]. The value of a hand wash before the disinfection period has been questioned recently in a draft European recommendation on surgical hand disinfection for two reasons [12]: First, a 1 min hand wash does not really reduce the number of skin bacteria to a relevant extent $[4,13]$. Second, it has been suggested in some studies that the efficacy of the alcohol-based hand rub is even reduced if hands are washed before disinfection $[13,14]$. The difference in efficacy of the same treatment was even more remarkable with and without a 2 min hand wash [15]. We can now add similar findings with an application time of 1.5 minutes.
Practical implications have to be adressed, too. The whole procedure of surgical hand disinfection is usually performed in the surgical theater block. If we assume that the surgeon enters the theater block with clean hands then there is no need to wash them before the disinfection period. If we assume that the surgeon enters the theater block with dirty hands then there is something wrong on another level. If we assume that hands have become dirty in the surgical theater block they should be washed immediately after soiling [1]. In that respect there is no reason to include a $1 \mathrm{~min}$ hand wash into the standard procedure of pre-operative treatments of hands especially since recent evidence points out some clear disadvantages of the hand wash.

The best efficacy was found without a hand wash and with additional drying time after the application of the hand rub. The immediate effect was only marginally better (0.03 $\log _{10}$-steps), the sustained effect improved somewhat more $\left(0.3 \log _{10}\right.$-steps). It is certainly correct that the efficacy of a hand rub which is applied for a specific time such as $1.5 \mathrm{~min}$ should be assessed exactly after $1.5 \mathrm{~min}$. At the same time the application by the healthcare workers will be different in the hospital as they have to await the evaporation of any residual alcohol from their hands before gloving. But the effect of the additional drying time has to our knowledge never been investigated with an alcohol-based hand rub although it has a clear practical relevance. We observed a trend towards a better overall efficacy if hands are allowed to dry for $1 \mathrm{~min}$ after the disinfection period. This finding was expected and can be explained by the additional and variable contact time of the alcohol with the skin. That is why the healthcare worker can expect that the "real efficacy" of an alcoholbased hand rub for surgical hand disinfection is to some extent better than measured according to EN 12791.

\section{Conclusion}

An application of the propanol-based hand rub for 1.5 min after $1 \mathrm{~min}$ hand wash fulfills the efficacy requirements of EN 12791. The efficacy can be improved to some 
extent by omitting the preceding hand wash and by awaiting the evaporation of the alcohol which is clinical practice anyway. The preceding hand wash has the most negative effect on the immediate effect. Based on our data hands should not be routinely washed before the disinfection period unless there is a good reason for it such as visible soil.

\section{Competing interests}

The second author is paid employee of Bode Chemie GmbH \& Co. KG, Hamburg, Germany.

\section{Authors' contributions}

GK and AK designed the study, NOH, GK, PK and TK analysed the data, NOH, GK and AK wrote the manuscript. All authors read and approved the final manuscript.

\section{Acknowledgements}

The study was funded by Bode Chemie GmbH \& Co. KG, Hamburg, Germany. The sponsor participated in the study design, analysis and interpretation of data, writing of the manuscript and the decision to submit the manuscript for publication.

\section{References}

I. Boyce JM, Pittet D: Guideline for hand hygiene in health-care settings. Recommendations of the healthcare infection control practices advisory committee and the HICPAC/SHEA/ APIC/IDSA hand hygiene task force. MMWR - Morbidity \& Mortality Weekly Report 2002, 5 I: I-45.

2. Anonymous: Händehygiene. Bundesgesundheitsblatt 2000 43:230-233.

3. Kampf G, Goroncy-Bermes P, Fraise A, Rotter M: Terminology in surgical hand disinfection - a new tower of Babel in infection control. Journal of Hospital Infection 2005, 59:269-27I.

4. Kampf G, Kramer A: Epidemiologic background of hand hygiene and evaluation of the most important agents for scrubs and rubs. Clinical Microbiology Reviews 2004, 17:863-893.

5. Parienti J], Thibon P, Heller R, Le Roux Y, von Theobald P, Bensadoun $H$, Bouvet $A$, Lemarchand $F$, Le Coutour $X$ : Hand-rubbing with an aqueous alcoholic solution vs traditional surgical hand-scrubbing and 30-day surgical site infection rates - a randomized equivalence study. The Journal of the American Medical Association 2002, 288:722-727.

6. Kampf G, Ostermeyer C, Heeg P: Surgical hand disinfection with a propanol-based hand rub: equivalence of shorter application times. Journal of Hospital Infection 2005, 58:304-310.

7. Kampf G, Ostermeyer C, Heeg P, Paulson D: Evaluation of two methods of determining the efficacies of two alcohol-based hand rubs for surgical hand antisepsis. Applied and Environmental Microbiology 2006, 72:3856-386I.

8. Hübner NO, Kampf G, Löffler H, Kramer A: Effect of a I minute hand wash on the bactericidal efficacy of consecutive surgical hand disinfection with standard alcohols and on skin hydration. International Journal of Hygiene and Environmental Health 2006, 209:285-291.

9. EN 12791:2005: Chemical disinfectants and antiseptics. Surgical hand disinfection. Test method and requirement (phase 2, step 2). Brussels, CEN - Comité Européen de Normalisation; 2005.

10. Pitten FA, Herdemann G, Kramer A: The integrity of latex gloves in clinical dental practice. Infection 2000, 28:388-392.

II. Kampf G, Meyer B, Goroncy-Bermes P: Comparison of two test methods for the determination of sufficient antimicrobial efficacy of three different alcohol-based hand rubs for hygienic hand disinfection. Journal of Hospital Infection 2003, 55:220-225

12. Labadie JC, Kampf G, Lejeune B, Exner M, Cottron O, Girard R, Orlick M, Goetz ML, Darbord JC, Kramer A: Recommendation fo surgical hand disinfection - requirements, implementation and need for research. A proposal by representatives of the SFHH, DGHM and DGKH for a European discussion. Journal of Hospital Infection 2002, 5 I:3 I2-3I5.

13. Rehork B, Rüden H: Investigations into the efficacy of different procedures for surgical hand disinfection between consecutive operations. Journal of Hospital Infection 199|, 19:I I5-127.

14. Heeg P, Ulmer R, Schwenzer N: Verbessern Händewaschen und Verwendung der Handbürste das Ergebnis der Chirurgischen Händedesinfektion? Hygiene + Medizin 1988, 13:270-272.

15. Rotter M, Koller W: Effekt der sequentiellen Anwendung von Chlorhexidinseife und einer alkoholischen $\mathrm{CHX}$-Präparation versus Flüssigseife und einer solchen Präparation bei der Chirurgischen Händedesinfektion. Hygiene + Medizin 1990, I5:437-440.
Publish with Biomed Central and every scientist can read your work free of charge

"BioMed Central will be the most significant development for disseminating the results of biomedical research in our lifetime. "

Sir Paul Nurse, Cancer Research UK

Your research papers will be:

- available free of charge to the entire biomedical community

- peer reviewed and published immediately upon acceptance

- cited in PubMed and archived on PubMed Central

- yours - you keep the copyright
BioMedcentral 